\title{
An Exergame Themed on the Power of Religious Belief for Stroke/Motor Rehabilitation
}

\author{
Rajat Singla \\ IIIT-Hyderabad \\ rajat.singla@research.iiit.ac.in
}

\author{
Ravi Raja Ganta \\ IIIT-Hyderabad \\ raviraja.ganta@students.iiit.ac.in
}

\author{
Kavita Vemuri \\ IIIT-Hyderabad \\ kvemuri@research.iiit.ac.in
}

\begin{abstract}
Post-stroke recovery depends on, a) motivation for physical exercises and b) trained therapists. The objective of the study was to examine the effect an exergame with a religious ritual as gameplay theme has on the motivation for lower limb motor therapy. Two games were designed and developed, a 'temple game' simulating the $\mathbf{2 4 0 0}$ odd steps to reach the sanctum of a famous deity located in India and a 'trekking game' with similar setup sans the religious symbols. A gym stair-stepper equipment was fitted with sensors to detect the action of climbing. Each physical step-action is mapped to a corressponding step in the virtual game. Data were collected from 4 stroke patients, 1 spinal cord injury patient and $\mathbf{1 3}$ healthy male participants. Motivation/immersion difference between the two games was compared. The post-test game experience questionnaire scored higher on immersion, motivation, and interest for the temple game. A remotely accessed and controlled exergame is considered important for doctors and patients due to the acute shortage of trained therapists. The findings open up a new genre of exergaming for neurorehabilitation customized to personal belief/faith structures. The authors do not propagate or promote any religious beliefs (+positive or -negative) but have sourced an existing belief system to build assistive devices for stroke rehab.
\end{abstract}

Keywords: exergame, religious belief, motivation, sensors, immersion, game design.

\section{INTRODUCTION}

Stroke leads to physical and cognitive disabilities The burden of a debilitating health condition due to stroke measured by the disability-adjusted life year (DALY) index is 795.57 per 100000 person-year [1]. Post-stroke physiotherapy is crucial for improving this index and the quality-of-life of a patient. Hence an urgent requirement for trained physio, occupational therapists, and stroke units which are very few in number (only in the few thousands) in India. Additionally, most stroke units are in major cities and patients from rural/smaller cities relocate for the period of rehabilitation adding to a financial burden on the family. It is imperative to make poststroke physio-cognitive therapy cheaper, accessible, automated and connected to the telemedicine infrastructure- that is, rehab exercise machines and diagnostic equipment connected to specialists and doctors using internet-of-things architecture. Importantly, emphasis should be on therapy sessions designed to motivate the patients.

Post-stroke, loss of function is noticed in upper and lower limb on one/both sides of the body. Therapy sessions for the lower limb include walking holding parallel bars, upper limb muscle strengthening, finger pressure, precision control of the arm, stationary cycling and step-climbing exercises. Technology enabled game intervention for motor therapy by the concept of exergames is a viable solution. Exergames integrate physical exercise coupled with motivating digital gameplay. By the way of unique game themes based on familiar real-life experiences and controls designed to mimic real-life motor movement exercises can be interesting. In this paper, we describe one such exergame titled 'power of belief', founded on religious belief structure and inspired by a ritual followed by the faithful. We show how an integrated system can increase player's enthusiasm level for exercise.

\section{BACKGROUND}

Games for health

Computer gaming technology and the integrable hardware has gained traction as serious assistive systems in motor/cognitive exercise for clinical (example: stroke) and healthy population. This is possible with the advent of tracking hardware interface devices like Nintendo Wii, Sony PlayStation, Kinect, leap motion sensors and virtual 
reality display mechanisms. The combination of the trackers, game and the display devices are shown to increase the immersiveness [2-4]. Studies have also investigated the comparative benefit of integrated hardware/software games as against traditional exercises [5][6]. In addition to intuitive hardware, specially designed games include ErgoActive, SunSportsGo, and Y-Move [7]. From a review of 27 studies [8] and other studies [9-11], it was found that a strong correlation exists between exergaming and physical activity. Though the studies on effectiveness over traditional exercise after normalizing for individual motivational levels are still being analyzed, exergame has caught the interest of the sports and health sector and also for clinical rehab therapy [12-18]. While neurosciences reviews[19-22] and survey[23] on interventions using games have highlighted the need to have naturalistic or personally consequential game designs to cater to individual motivation levels.

The biggest challenge to exergame designers is to incorporate cultural and emotional factors in the game narrative and play. Most of the exergames have running, walking, cycling or climbing actions with no compelling narratives and hence when placed in a cultural context have little or no direct connotation to real-life experiences. Our contribution is one such unique game design inspired by a religious belief-based ritual integrated as an exergame. The virtual game simulates a pilgrim ritual of climbing nearly 2400 steps to reach the sanctum of the presiding deity. The ritual of climbing the steps to the top of the hill is considered important for believers. To test the validity of the religious belief's role in exercise, a similar game without any religious symbolism (objects or hymns) emulating a trekking exercise was developed. While religion and faith are important for most healthy individuals it holds higher significance after an illness. But, in this design, we do not discourse on religion or spirituality but only use a physical ritual considered as an experience of faith or devotion as a game narrative.

\subsection{BELIEF/FAITH \& MOTIVATION}

Religion is a set of beliefs and rituals while spirituality is a search for the meaning of life, one's values and relationship with God/higher power while spirituality adds meaning to life[24]. There are many studies reporting the positive influence of religion and spirituality [25-32] on recovery/coping by patients especially and some that reject the correlation [33], but very few empirical studies have been carried out. Religion and in particular the associated physical rituals (going by foot to reach a place of worship, lighting candles, ringing bells etc.,) are an important part of the culture's belief structure but are rarely acknowledged as a physical exercise. In this paper, we do not propose a new theory on religion or belief but accept it as a strong influencer in believers. We experiment with game narrative tapping into spirituality and its effect on motivating certain physical activity. Hence, this paper opens up a new genre of game narrative - faith and religion in exergames.

\section{DESIGN OF THE GAME}

The game developed (in Unity 3D game engine) is a first-person camera view and a virtual replication of a famous temple located in south India. To reach the main shrine the players 'climb' 2400 odd steps. The hills, the steps and the numerous small shrines of other deities as in real-world were simulated. The music for the temple version is popular hymns and songs associated with the deity and variants for each small shrine. In the trekking version, the structures along the way include cafeterias, viewpoints and sit-outs and non-specific instrumental music is played. The other objects include trees, structures housing the deities(temple), sit-outs or viewpoints (trekking), a winding stairway, barrels of water and fruits. At intermediate reststops, fruits/water is 'consumed' and the health score increases. A counter records each shrine visited and same converted as 'blessings' score (temple), and in the trekking version visit to each viewpoint adds to the score. As the player performs the action of climbing (on a modified step climber gym equipment), the number of steps is counted and the current latitude/longitude position is displayed on a real geographical map embedded in the display for a sense of immersion. Pop-up windows with information about the next small shrine (temple) or viewpoint (trekking) and the presence of water/fruits are displayed at regular intervals. The screenshots of the two versions of the exergames are shown in figure 1.

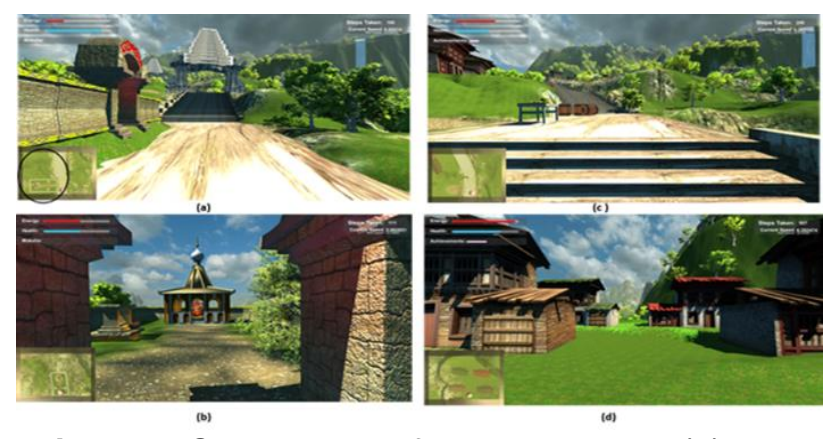

Figure 1: Screenshots of the exergames. (a) The entrance view of the temple game. The inset highlighted by a circle on the lower left corner is the position of the player in the virtual space with respect to the lat/long coordinates in the representative map real-world geographical world. (b) One of the smaller shrines that dot the stairway to the main shrine. (c) The view of the trekking game. (d) one of the tourist spots in the trekking game. 


\section{HARDWARE}

A step climber gym equipment was rigged with two ultrasonic trans-receiver unit (HC SR04) positioned below each step. The differential signal from the steps is sent as input to the game through an Arduino Mega board (2560 R3). A small 'click' touch button on the handle of the step climber equipment is provided for the player to navigate into a shrine or tourist spot. A large 32-inch LCD screen connected to a high-end CPU/GPU machine was placed at a convenient distance from the stroke patients while the game graphics were projected on a $6 \mathrm{ft} \times 4 \mathrm{ft}$ screen for the healthy participants.

\section{METHODOLOGY}

Participants: Healthy participant set - Thirteen males (age 20-30 years), education: maximum high-school, none of them reported any medical condition or currently on any medication. The participants gave their informed consent. Of the 13 participants, 4 of them reported having converted to Christianity from the Hindu religion. Stroke patient set: Four stroke patients and 1 spinal-cord injury patient recruited at a rehab center. The details are given in table 2 . While four of the patients follow the Hindu religious order, one was of the Muslim faith. Each participant (from both sets) played both the games for around 30 minutes with a gap of 4-8 hours. One patient gave data for only one version of the game. Game testing on human subjects has the approval of the ethics committee of the Institute and all patient data was collected under the supervision of the doctors and therapists at the rehab center.

\section{EXPERIMENT}

The working of the step climber gym equipment was explained to the participant. The presentation of the two versions of the game was counterbalanced to control order effects. A time gap between the two trails was set to reduce effects of stress or exertion due to the step climbing physical activity. Post experiment with both versions, they were asked to rate on a scale of 1-10 (with 10 being the maximum) taking art, gameplay, and immsersiveness as parameters. The background music and its role in the immersion were similarly rated. Questions on game experience were asked orally and responses noted. The number of steps climbed by the healthy participants is reported, but that of the patients was not as they could not continue on the exercise for long periods at one stretch.

\section{RESULTS}

Table 2 lists the rating $1-10$ (10 being the maximum) provided by each patient. Overall the temple version 's art and gameplay scored high compared to trekking in people of Hindu faith, significance was not observed with a two-sample Ttest. Though all the patients found the trekking version equally interesting they mentioned that repetitive use of it might not hold the same excitement levels. They all unanimously voted for exergame for rehabilitation over regular exercise, as can be observed from the lower scores for normal exercises. On experience, the patients following the Hindu faith expressed a sense of peace and feeling of actually climbing the temple hill while the patient of Muslim faith rated the trekking game higher. Patient 4 did not give a number on the scale but said that the temple game was better. Interestingly, two patients who reported a higher frequency of visits to religious places in a month rated the temple game one or two points lower than a patient who visited religious places less often. Though no strong inference can be made with such sparse data, it raises the question of religious belief post trauma.

The ratings on a similar scale were also provided by the healthy participants and presented in Table 1. A paired two-sample T-test on the scores for the temple and trekking show a p-value of 0.019 (mean $=8.83$; variance $=1.78$; two-tailed) for the art/gameplay, while for music the p-value is 0.0002 ( mean $=9 ;$ variance $=1.09$ ' two-tailed $)$. Interestingly, two from the healthy participant's group following the Christian faith rated the trekking game higher than the temple game while two gave an equal rating for both but all the four rated temple music higher than the trekking game music. A possible explanation might be familiarity bias that is, the temple music is heard more often in public places of worship. The music rating for the trekking version is lower and needs to be improved.

Table 1: The rating on the scale 1-10, with 10 being maximum for the art/gameplay and the music for the temple and trekking versions of the exergame. * indicate participants who had converted to Christianity faith. The number of steps climbed is presented.

\begin{tabular}{|l|l|l|l|l|l|l|}
\hline $\begin{array}{l}\text { Partic } \\
\text { ipant }\end{array}$ & $\begin{array}{l}\text { Temple } \\
\text { (art, } \\
\text { gameplay) }\end{array}$ & $\begin{array}{l}\text { Temple } \\
\text { (Music) }\end{array}$ & $\begin{array}{l}\text { Trekking } \\
\text { (art, } \\
\text { gameplay) }\end{array}$ & $\begin{array}{l}\text { Trekking } \\
\text { (Music) }\end{array}$ & $\begin{array}{l}\text { Steps } \\
\text { (Temple) }\end{array}$ & $\begin{array}{l}\text { Steps } \\
\text { (Trekking) }\end{array}$ \\
\hline 1 & 8 & 10 & 8 & 5 & 2142 & 2164 \\
\hline 2 & 10 & 10 & 6 & 4 & 2157 & 2160 \\
\hline 3 & 10 & 10 & 8 & 6 & 2298 & 2163 \\
\hline 4 & 10 & 8 & 6 & 6 & 2274 & 2161 \\
\hline $5^{\star}$ & 6 & 8 & 8 & 8 & 2241 & 2280 \\
\hline $6^{\star}$ & 8 & 8 & 10 & 6 & 2278 & 2256 \\
\hline 7 & 10 & 10 & 6 & 4 & 2229 & 2138 \\
\hline $8^{\star}$ & 8 & 8 & 8 & 6 & 2274 & 2195 \\
\hline 9 & 10 & 10 & 4 & 2 & 2165 & 2150 \\
\hline 10 & 10 & 10 & 4 & 2 & 2242 & 2200 \\
\hline 11 & 8 & 8 & 6 & 4 & 2283 & 2173 \\
\hline 12 & 8 & 10 & 6 & 2 & 2279 & 2122 \\
\hline $13^{\star}$ & 8 & 8 & 8 & 6 & 2238 & 2182 \\
\hline
\end{tabular}


All the healthy participants (including four following the Christian faith) had climbed the steps to the real-temple and were familiar with the spatial layout of the temple and mentioned the anticipation of reaching the top as strong motivation. The number of steps climbed (Table 1) was also noted though the participants (healthy and patients) were instructed to stop at any time if experiencing discomfort or exhaustion. Almost all of them had crossed the 2000 steps mark in both game versions. But, nine participants climbed more number of steps in the temple version, a difference noticed in the within-subject data too. The score on blessings and health shown on the screen for every shrine visited and steps climber was an emotional experience, as reported.

\begin{tabular}{|c|c|c|c|c|c|c|c|c|c|c|}
\hline $\begin{array}{l}\text { Partic } \\
\text { ipant }\end{array}$ & $\begin{array}{l}\text { Health } \\
\text { Problem }\end{array}$ & $\begin{array}{l}\text { Time } \\
\text { period }\end{array}$ & Age & Religion & Theist & $\begin{array}{l}\text { Religious } \\
\text { place visit per } \\
\text { month }\end{array}$ & $\begin{array}{l}\text { Temple } \\
\text { (art and } \\
\text { gameplay) }\end{array}$ & $\begin{array}{l}\text { Trekking (art } \\
\text { and } \\
\text { gameplay) }\end{array}$ & $\begin{array}{l}\text { Normal } \\
\text { Exercise } \\
\text { (immersiveness } \\
\text { score) }\end{array}$ & $\begin{array}{l}\text { Prefer } \quad \text { Normal } \\
\text { exercise/Exergame }\end{array}$ \\
\hline 1 & $\begin{array}{l}\text { Left Body } \\
\text { Stroke }\end{array}$ & 2.5 Month & 40 & Hindu & Yes & 30 & 8 & 6 & 6 & Exergame \\
\hline 2 & $\begin{array}{l}\text { Left Body } \\
\text { Stroke }\end{array}$ & 2 Year & 48 & Hindu & Yes & 4 & 10 & 8 & 5 & Exergame \\
\hline 3 & $\begin{array}{l}\text { Right Body } \\
\text { Stroke }\end{array}$ & 1 Year & 55 & Hindu & Yes & 30 & 9 & 6 & 5 & Exergame \\
\hline 4 & $\begin{array}{l}\text { Right Body } \\
\text { Stroke }\end{array}$ & & 32 & Hindu & Yes & 2 & Better & - & - & Exergame \\
\hline 5 & $\begin{array}{l}\text { Spinal Cord } \\
\text { Pain, left leg }\end{array}$ & 4.5 Month & 65 & Muslim & Yes & 30 & 5 & 8 & 7 & Exergame \\
\hline
\end{tabular}

Table 2: The details of the patients and the rating for the temple and trekking game

\section{DISCUSSION}

The aim of the study was to highlight an unexplored, contentious but important attribute that of personal religious belief/faith in recovery post a physically debilitating trauma like stroke/paralysis. We positioned our study on existing rituals associated with a particular religion and tested endurance/motivation in the physical exercise. The design for a game symbolizing religious theme emerged from exergames developed for stroke rehabilitation in the lab and inputs received especially from female patients. Their wish to get back their lower limb strength post therapy and the desire to visit the famous temple seeded the idea for this game. In this study, we do not question or take a position on the question of the existence of God or the moral questions of the belief structure. We base it on our limited understanding that religious belief plays a significant role in individual and societal behavior while also being conscious of subjective differences in idolatry and importantly the compartmentalization of rituals and belief. Hence, for the participants, both healthy and the patients, we hypothesized that faith being essential, an associated ritual will have an effect on the outcome of physical therapy.

Our findings support the hypothesis to a large extent. First, in the healthy adults virtualizing a belief driven ritual task positively affected the enthusiasm and motivation to complete the task evidenced by the comparative rating for a similar task with no religious symbolism. This affirms the distinguishing role of religious rituals as motivators in the designed exergame. The role of devotional background music for the immersive experience is also affirmed by the music effect rating for each version of the game.

Hence, exergame and religious-themed games, in particular, can be considered as not only motivational therapy but also as a substitute for real-life religious experience.

To increase the motivation quotient, the inclusion of roles like priests as interactive Al characters can be introduced. Another idea is to convert game rewards to real-life tokens to be redeemed in temples or tourists' spots. In conclusion, from the preliminary data, we can infer the potential of exergaming using low-cost off-the-shelf hardware with the religious ritual theme as motivating theme for clinical and healthy populations. A limitation of the study is the smaller set of stroke/injury patients which effects the strength of any claim.

\section{REFERENCES}

1. Banerjee, T. K., Dutta, S., Ray, B. K., Ghosal, M., Hazra, A., Chaudhuri, A., \& Das, S. K. (2013). Disease burden of stroke in Kolkata, India: derivation of disability-adjusted life years by a direct method. Neuroepidemiology, 41(2), 8893.

2. Pasco, D., Roure, C., Kermarrec, G., Pope, Z., \& Gao, Z. (2017). The effects of a bike active video game on players' physical activity and motivation. Journal of Sport and Health Science, 6(1), 25-32. 
3. Buttussi, F., \& Chittaro, L. (2010). Smarter phones for healthier lifestyles: An adaptive fitness game. IEEE Pervasive Computing, 9(4), 51-57.

4. Leatherdale, S. T., Woodruff, S. J., \& Manske, S. R. (2010). Energy expenditure while playing active and inactive video games. American journal of health behavior, 34(1), 31-35.

5. Haddock, B. L., Siegel, S. R., \& Wikin, L. D. (2009). The addition of a video game to stationary cycling: The impact on energy expenditure in overweight children. The open sports sciences journal, 2, 42.

6. Bonetti, A. J., Drury, D. G., Danoff, J. V., \& Miller, T. A. (2010). Comparison of acute exercise responses between conventional video gaming and isometric resistance exergaming. The Journal of Strength \& Conditioning Research, 24(7), 1799-1803.

7. Göbel, S., Hardy, S., Wendel, V., Mehm, F., \& Steinmetz, R. (2010, October). Serious games for health: personalized exergames. In Proceedings of the 18th ACM international conference on Multimedia (pp. 1663-1666). ACM.

8. Sween, J., Wallington, S. F., Sheppard, V., Taylor, T., Llanos, A. A., \& AdamsCampbell, L. L. The role of exergaming in improving physical activity: a review. Journal of Physical Activity and Health, 11(4), (2014). 864-870.

9. Macvean, A., \& Robertson, J. (2013, April). Understanding exergame users' physical activity, motivation and behavior over time. In Proceedings of the SIGCHI Conference on Human Factors in Computing Systems (pp. 1251-1260). ACM.Bandura, A. Self-Efficacy Mechanism in Human Agency. American Psychologist 37, 2 (1982), 122-147.

10. Bandura, A. (1982). Self-efficacy mechanism in human agency. American psychologist, 37(2), 122.

11. Biddiss, E., \& Irwin, J. (2010). Active video games to promote physical activity in children and youth: a systematic review. Archives of pediatrics \& adolescent medicine, 164(7), 664-672.

12. Alankus, G., \& Kelleher, C. (2012, May). Reducing compensatory motions in video games for stroke rehabilitation. In Proceedings of the SIGCHI Conference on Human Factors in Computing Systems (pp. 2049-2058). ACM.

13. Alankus, G., Lazar, A., May, M., \& Kelleher, C. (2010, April). Towards customizable games for stroke rehabilitation. In Proceedings of the SIGCHI Conference on Human Factors in Computing Systems (pp. 2113-2122). ACM.

14. Hernandez, H. A., Graham, T. C., Fehlings, D., Switzer, L., Ye, Z., Bellay, Q., ... \& Stach, T. (2012, May). Design of an exergaming station for children with cerebral palsy. In Proceedings of the SIGCHI Conference on Human Factors in Computing Systems (pp. 2619-2628). ACM.

15. Brown, R., Sugarman, H., and Burstin, A. Use of the Nintendo Wii Fit for the treatment of balance problems in an elderly patient with stroke: a case report. International Journal of Rehabilitation Research 32, (2009), 109-110.

16. Saposnik, G., Teasell, R., Mamdani, M., Hall, J., Mcllroy, W., Cheung, D., ... \& Bayley, M. (2010). Effectiveness of virtual reality using Wii gaming technology in stroke rehabilitation: a pilot randomized clinical trial and proof of principle. Stroke, 41(7), 1477-1484.

17. Balaam, M., Rennick Egglestone, S., Fitzpatrick, G., Rodden, T., Hughes, A. M., Wilkinson, A., ... \& Mawson, S. (2011, May). Motivating mobility: designing for lived motivation in stroke rehabilitation. In Proceedings of the SIGCHI Conference on Human Factors in Computing Systems (pp. 3073-3082). ACM.

18. Shah, N., Amirabdollahian, F., \& Basteris, A. (2014, June). Designing motivational games for stroke rehabilitation. In Human System Interactions (HSI), 2014 7th International Conference on (pp. 166-171). IEEE.

19. Monteiro-Junior, R. S., Figueiredo, L. F. D. S., Maciel-Pinheiro, P. D. T., Abud, E. L. R., Engedal, K., Barca, M. L., ... \& Deslandes, A. C. (2017). Virtual RealityBased Physical Exercise With Exergames (PhysEx) Improves Mental and Physical Health of Institutionalized Older Adults. Journal of the American Medical Directors Association, 18(5), 454-e1.

20. Bamidis, P. D., Vivas, A. B., Styliadis, C., Frantzidis, C., Klados, M., Schlee, W., ... \& Papageorgiou, S. G. (2014). A review of physical and cognitive interventions in aging. Neuroscience \& Biobehavioral Reviews, 44, 206-220.

21. Fissler, P., Küster, O., Schlee, W., \& Kolassa, I. T. (2013). Novelty interventions to enhance broad cognitive abilities and prevent dementia: 
synergistic approaches for the facilitation of positive plastic change. In Progress in brain research (Vol. 207, pp. 403-434). Elsevier.

22. Harris, D. M., Rantalainen, T., Muthalib, M., Johnson, L., \& Teo, W. P. (2015). Exergaming as a viable therapeutic tool to improve static and dynamic balance among older adults and people with idiopathic Parkinson's disease: a systematic review and metaanalysis. Frontiers in aging neuroscience, 7, 167.

23. Hung, Y. X., Huang, P. C., Chen, K. T., \& Chu, W. C. (2016). What do stroke patients look for in game-based rehabilitation: a survey study. Medicine, 95(11).

24. Maugans, T. A. (1996). The spiritual history. Archives of family medicine, 5(1), 11-16.

25. Pargament, K. I., Koenig, H. G., Tarakeshwar, N., \& Hahn, J. (2001). Religious struggle as a predictor of mortality among medically ill elderly patients: A 2-year longitudinal study. Archives of internal Medicine, 161(15), 1881-1885.

26. Clark, P. A., Drain, M., \& Malone, M. P. (2003). Addressing patients' emotional and spiritual needs. The Joint Commission Journal on Quality and Safety, 29(12), 659-670.

27. Rippentrop, A. E., Altmaier, E. M., Chen, J. J., Found, E. M., \& Keffala, V. J. (2005). The relationship between religion/spirituality and physical health, mental health, and pain in a chronic pain population. Pain, 116(3), 311-321.

28. Smith, T. B., McCullough, M. E., \& Poll, J. (2003). Religiousness and depression: evidence for a main effect and the moderating influence of stressful life events. Psychological bulletin, 129(4), 614.

29. Underwood-Gordon, L., Peters, D. J., Bijur, P., \& Fuhrer, M. (1997). ROLES OF RELIGIOUSNESS AND SPIRITUALITY IN MEDICAL REHABILITATION AND THE LIVES OF PERSONS WITH DISABILITIES: A Commentary1. American Journal of Physical Medicine \& Rehabilitation, 76(3), 255-257.
30. Wilson, C. S., Forchheimer, M., Heinemann, A. W., Warren, A. M., \& McCullumsmith, C. (2017). Assessment of the relationship of spiritual well-being to depression and quality of life for persons with spinal cord injury. Disability and rehabilitation, 39(5), 491-496

31. Giaquinto, S., Spiridigliozzi, C., \& Caracciolo, B. (2007). Can faith protect from emotional distress after stroke?. Stroke, 38(3), 993-997.

32. Hodge, D. R. (2001). Spiritual assessment: A review of major qualitative methods and a new framework for assessing spirituality. Social work, 46(3), 203-214.

33. Yamey, G., \& Greenwood, R. (2004). Religious views of the 'medical'rehabilitation model: a pilot qualitative study. Disability and Rehabilitation, 26(8), 455-462. 